\title{
The Electric Vehicle Power Design and The Matching Characteristics Analysis of The Transmission System
}

\author{
Lei Zhang ${ }^{{ }^{1}}$, Guili $\mathrm{Hao}^{1}$, Xiumin Yang ${ }^{2}$, Chunyang Zhou ${ }^{2}$ \\ ${ }^{1}$ School of Mechanical Engineering and Automation, Northeastern University, No.11, Lane 3, WenHua \\ Road, HePing District, Shenyang 110006, China, Ph./Fax: +86 2483687633 \\ ${ }^{2}$ Department of Automatic Controls, Shenyang Institute of Engineering, No. 18, Puchang Road, Shenbei \\ New District, Shenyang 110136, China, Ph./Fax: +86 2431975569 \\ ${ }^{*}$ Corresponding author, e-mail: leizhang526@163.com
}

\begin{abstract}
According to the requirements of the performance parameters of chongqing lifan E520 cars, electric vehicles with pure mechanical electronically controlled continuously variable transmission (CVT) were designed and developed. The power function of traction motor was designed firstly. According to the vehicle performance and motor parameters, matching parameters of CVT were calculated and confirmed. The parameters of maximum speed, acceleration time and gradeability of CVT were analyzed and compared. The parameters of the battery pack were designed according to the acceleration capability of electric vehicles, continued driving mileage. Currently, the electric vehicles equipped with pure mechanical electronically controlled CVT have passed the bench test and loading operation. These have proved that the dynamic design and driveline matching design in this paper were correct and achieved a predetermined operating performance and power performance indicator.
\end{abstract}

Keywords: electric vehicle, transmission system, power design, the matching design

Copyright (c) 2013 Universitas Ahmad Dahlan. All rights reserved.

\section{Introduction}

The performance indicators of conventional vehicle include economy, dynamic performance, braking performance, smooth performance, handling stability and other related performances. For the difference of power supply and drive system, the requirements of the performance indicators are different with conventional vehicle. Pure electric vehicle sees electrical energy stored in batteries as a source of energy, so the important indicator to measure the performance of the electric vehicle is the biggest continue driving range of the electric vehicle by one time charge. Because it does not have internal combustion engine and burn fuel, index requirements of fuel economy does not need. Besides, electric vehicle widely use motor drive system and its power element is motor. The output performance of motor is different with internal combustion engine [1]. So the dynamic performance of the electric vehicle is quite different with conventional vehicle.

Motor drive system of electric vehicle translates outputting power of battery into rotational energy of wheel, so it can drive the operation of the electric vehicle. It is the core of the electric vehicle, determining the performance of electric vehicle. Its energy transformation efficiency also affects directly the maximum mileage of electric vehicle. Thus, the studying electric vehicle drive system and improving the efficiency of the motor have an important role in improving the economic performance of the electric vehicle [2].

According to the requirements of the performance parameters of chongqing lifan E520 cars, the electric vehicle equipped with pure mechanical electronic continuously variable transmission is developed. According to the requirements of performance parameters of the original car, dynamic design and planning of electric vehicle are made, and matching characteristics of the drive system are analyzed.

\section{The Design and Analysis of Total Vehicle Parameter and Dynamic}

Due to the energy density of battery power of the electric vehicle is still low and the vehicles can not get longer mileage depending on increasing the number of batteries 
because of size and weight, so in development phase, selecting of power parameters and taking advantage of the performance of the various parts are very important [3].

The electric vehicle parameters in this paper are based on the Chongqing Lifan Automobile E520, and the performance parameters are announced by the company. The total vehicle parameter is shown in Table 1.

Table 1. Total Vehicle Parameter

\begin{tabular}{cc}
\hline Vehicle parameters & Parameter value \\
\hline Fully loaded weight $\mathrm{ma} / \mathrm{kg}$ & 1895 \\
Vehicle weight $\mathrm{m} / \mathrm{kg}$ & 1500 \\
Air resistance coefficient Cd & 0.3 \\
Rolling resistance coefficient on a good road & 0.012 \\
Frontal area A/ m2 & 2.3 \\
Wheel rolling radius $\mathrm{r} / \mathrm{m}$ & 0.298 \\
Wheelbase $\mathrm{mm}$ & 2605 \\
Front / rear wheel spacing /mm & $1470 / 1460$ \\
The main reduction ratio i0 & 4.308 \\
Transmission system efficiency $\eta$ & 0.9 \\
\hline
\end{tabular}

According to the requirements of performance parameters of pure electric vehicles, connecting with the customers' requirements on vehicle performance of the car, developing requirements of the pure electric vehicle performance are as follows:

(1) Maximum speed $\geq 90 \mathrm{~km} / \mathrm{h}$;

(2) Maximum Climbing gradient $\geq 20 \%$;

(3) Acceleration time: $0-50 \mathrm{~km} / \mathrm{h} \leq 9 \mathrm{~s}, 50-80 \mathrm{~km} / \mathrm{h} \leq 10 \mathrm{~s}$;

(4) $60 \mathrm{~km} / \mathrm{hConstant}$ driving continue driving range $\geq 150 \mathrm{~km}$.

\section{Parameter Design of Traction Motor Power}

For drive motor of electric vehicle, we need to make sure three parameters, Rated power $P_{e}$, Overload power $P_{\text {emax }}$ and Peak torque $T_{\max }$. The choices of performance parameters of the motor should mainly consider the vehicle dynamic performance, so this chapter should analyze the needs of the vehicle power firstly.

\subsection{Traction Motor Power}

Based on the related theory, traction motor rated power is limited by maximum speed, maximum climbing gradient, and is checked by the acceleration time.

(1) The calculation of motor rated power is based on the highest speed

The power consumption of the vehicle increases with speed, and the speed of the electric vehicle is generally lower than the highest speed, so it can have appropriate backup power. The conditions of rated power $P_{e}$ meeting the vehicle with the highest speed constant driving are:

$$
P_{\mathrm{e}} \geq \frac{1}{\eta}\left(\frac{m g f}{3600} V_{\max }+\frac{C_{d} A}{76140} V_{\text {max }}^{3}\right)
$$

In the formula: $m$ is the quality of the vehicle, $g$ is gravitational acceleration, $f$ is rolling resistance coefficient, $C_{d}$ is air resistance coefficient, $A$ is windward area, $\eta$ is the transmission efficiency, $V_{\max }$ is a maximum speed.

To calculate with top speed of $90 \mathrm{~km} / \mathrm{h}$, the power of electric auto service quality in operation is $15.05 \mathrm{~kW}$.

(2) The calculation of motor rated power is based on the maximum climbing gradient

When electric vehicles climb maximum climbing gradient in a certain speed $V$, the calculation of driving power can neglect the power produced by resistance of acceleration. 


$$
P_{i} \geq \frac{1}{\eta}\left(\frac{m g f}{3600} V+\frac{m g i}{3600} V+\frac{C_{d} A V^{3}}{76140}\right)
$$

When climbing gradient of electric vehicles counts for $20 \%$ in speed $20 \mathrm{~km} / \mathrm{h}$, the power of electric vehicles is $19.64 \mathrm{~kW}$. Changing relations of motor power with climbing gradient and climbing speed is as follows:

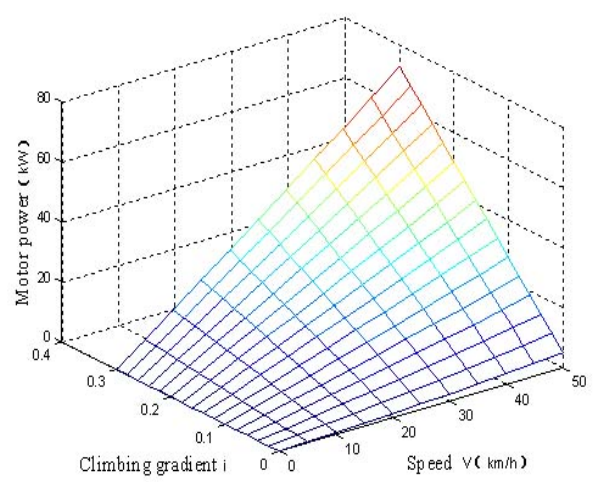

Figure 1. The Motor Power along the Speed and Slope Change Relationship

According to the above results, select the motor rated power for $20 \mathrm{kw}$. In market, the most commonly used traction motor power is 3 times than rated power [4]. It can meet power performance requirement in the acceleration and climbing mode.

\subsection{Traction Motor Torque}

The choice of motor maximum torque should satisfy the requirements of vehicle starting torque and maximum climbing gradient. At the same time, it should determine by the biggest transmission ratio and the biggest climbing gradient of transmission system.

$$
T_{\max } \geq \frac{1}{\eta} \cdot \frac{m g\left(f \cdot \cos a_{\max }+\sin a_{\max }\right) r}{i_{\max }}
$$

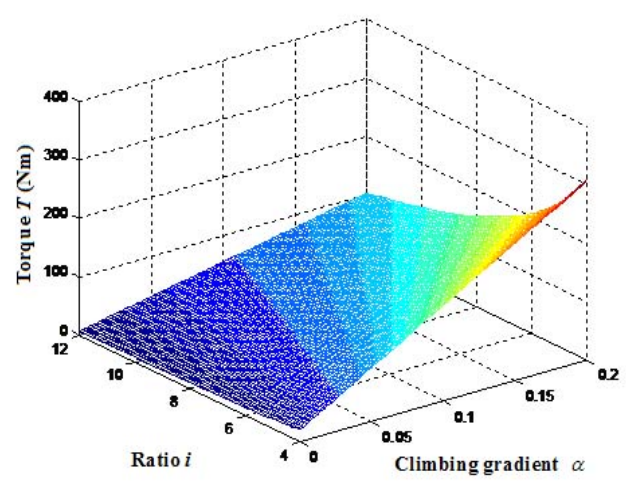

Figure 2. Torque Change Relation with Transmission Ratio and Slope

In the formula: $r$ is wheel rolling radius; $\alpha_{\max }$ is maximum Climbing gradient; $f$ is rolling resistance coefficient; $\mathrm{mg}$ is vehicle weight; $\eta$ is drive system overall efficiency; $i_{\max }$ is maximum ratio.

When vehicle climbing gradient is sure, motor torque decreases with the transmission ratio increasing, but too much ratio will affect the vehicle's maximum speed, so the choice of 
traction motor torque must be combined with many factors. Torque change relation with transmission ratio and slope see Figure 2.

\subsection{The Choice of Electric Vehicle Battery}

Power battery is the only source of power and energy carrier of electric vehicle, providing energy for the drive motor and accessory power electronic equipment. Power battery performance parameters directly affect the dynamic performance and economy of the vehicle, being one of the cores of the early electric vehicle design. Matching parameters of electric vehicle power battery include the selections of battery power, battery capacity and battery voltage [5].

The matching of pure electric vehicle battery parameters mainly includes battery capacity and battery voltage level [8]. In the matching battery voltage level, the matching battery voltage level must keep consistent with drive motor voltage level and can meet the requirements of the voltage variation; at the same time, as the pure electric vehicles equip with electric air conditioning, electric windshield wiper and other accessories, it can generate additional power consumption. The matching battery voltage level must be higher than the drive motor rated voltage [7-9].

Battery voltage levels can be determined by the monomer of the battery voltage, connecting method and cell number. According to the actual situation of the selected models, the monomer battery rated voltage is determined as $3.2 \mathrm{~V}$, and connection mode selects series connection.

In order to guarantee dynamic performance of the pure electric vehicle and one times charging gaining mileage, the numbers of single cells should be based on the maximum output power of the drive motor and meet the biggest energy of the driving range index.

(1) According to the maximum output power of the drive motor to choose electric vehicle battery quantity.

$$
N_{1}=\frac{P_{E \max }}{P_{b \max } \eta_{E} \eta_{E C}}
$$

In the formula: $P_{E \max }$ is the maximum output power of drive motor; $P_{b \max }$ is the maximum output power of a single cell ; $\eta_{E}$ is the working efficiency of the drive motor; $\eta_{E C}$ is the working efficiency of the motor controller.

(2) According to meet the demand of the driving range for the biggest energy to choose electric vehicle battery quantity

When pure electric vehicles constantly drive in speed $V$, needing power is:

$$
P=\frac{1}{3600 \eta_{T}}\left(m g f+\frac{C_{D} A V^{2}}{21.15}\right) V
$$

The energy of needing driving range indicator is:

$$
W=\frac{s \cdot p}{v}
$$

In the formula: $W$ is battery energy, $V$ is vehicle running speed; $S$ is continue driving range indicator of pure electric vehicle with speed $V ; p$ is demand power in speed $V$.

The cell number for meeting the driving range indicator:

$$
N_{2}=\frac{1000 \times W}{U_{1} \cdot C \cdot \xi_{\text {soc }}}
$$

In the formula: $U_{1}$ is rated voltage of monomer battery; $C$ is rated capacity of monomer battery; $\xi_{\text {soc }}$ is discharge depth of the battery, generally $80 \%$. 
To sum up, the numbers of single cell are:

$$
N \geq \max \left(N_{1}, N_{2}\right)
$$

\section{Design of Driving System Matching Parameter}

The drive system of car has two functions: The first is to amplify torque in the drive motor output shaft based on the total transmission ratio, and transfer to the driving wheels; the second is to narrow the drive motor speed based on the total transmission ratio, and convert into corresponding speed; considering the transmission efficiency can get power conservation. Overall ratio in electric vehicles is the product of the transmission ratio of components in the transmission system, namely $i_{t}=i_{0} \cdot i_{g}$. Overall ratio limit in drive system can be determined by the equation $[4,5]$ :

$$
i_{t} \leq \frac{0.377 n_{\max } r}{V_{\text {amax }}}
$$

The lower limit of the total transmission ratio transmission system can have the two sure ways;

(1) The maximum speed of the motor corresponding maximum output torque and speed limit corresponding driving resistance ratio determine the lower limit of transmission system:

$$
i_{t} \geq \frac{F_{v \max } \cdot r}{\eta T_{v \max }}
$$

In it, $T_{v \max }$ is output torque of motor with the highest speed, $F_{v \max }$ is the driving resistance in speed limit.

$$
\left\{\begin{array}{l}
F_{v \max }=m g f+\frac{C_{d} \cdot A}{21.15} \cdot V_{a \max }^{2} \\
T_{v \max }=9550 \frac{P_{e}}{n_{\text {m max }}}
\end{array}\right.
$$

(2) The motor maximum output torque and maximum Climbing gradient corresponding driving resistance ratio determine the lower limit :

$$
i_{t} \geq \frac{F_{\alpha \max } \cdot r}{\eta T_{\alpha \max }}
$$

In it, $F_{a \max }$ is driving resistance in maximum Climbing gradient, $T_{a \max }$ is motor maximum output torque, $\mathrm{Nm}$.

$$
F_{v \max }=m g\left(f \cos \alpha_{\max }+\sin \alpha_{\max }\right)+\frac{C_{d} \cdot A}{21.15} V_{a \max }^{2}
$$

Transmission ratio is determined by electric vehicle Climbing gradient and motor torque capacity, namely:

$$
i_{g} \geq \frac{m g\left(f \cos \alpha_{\max }+\sin \alpha_{\max }\right) r}{T_{\max } i_{0} \eta}
$$


From the above parameters comparison and calculation formula can obtain: transmission ratio of electric vehicle gearbox has no influence on the choice of motor power, and motor speed and torque have internal relations with ratio. For the performance of the total vehicle, we must give consideration to design principles of the minimum and maximum ratio. Data analysis and contrast can be seen, abilities of electric vehicles carrying EMCVT maximum speed, acceleration time and maximum climbing gradient are more than carrying FGR electric vehicle.

\section{Summary}

Based on the chongqing lifan automobile E520, electric car vehicle parameter is planning. According to the performance requirements of electric vehicle, the power performance of the traction motor, the matching parameters of EMCVT, and the corresponding parameters of power battery are designed. At present, the developed electric car with EMCVT has been run through the loading experiment. The design of Vehicle dynamic performance and matching design of transmission system in this paper are confirmed. The designed performance and control target is implemented.

\section{Acknowledgement}

This project was supported by the science and technology key project of Liaoning province, P.R. China (No. 2009220015).

\section{References}

[1] W RYU, H KIM. CVT ratio control with consideration of CVT system loss. International Journal of Automotive Technology. 2008; (9): 459-465.

[2] Yves Rothenbuhler. CVT Servo-Pump Flow Control. Koyo Engineering Journal. 2007; 1003: 23-26.

[3] Kazutaka Adachi, Yoshimasa Ochi, Kimio Kanai. Development of CVT control system and its use for fuel-efficient operation of engine, Asian Journal of Control. 2006; (8): 219-226.

[4] Wei Dong. Study on Integrate Control of Engine and CVT for Vehicle Running in the Slope. Changchun of China:Jilin University. 2007.

[5] Fenzhu Ji, Feng Gao, Zhixin Wu. Parameter design for power train and simulation of dynamic performance of electrical vehicles. Journal of Beijing University of Aeronautics and Astronautics. 2006; 32(11): 108-111.

[6] Lei ZHANG, Xiaomei CONG, Hujian Pan, Zuge CAI, Xiumin YANG. The Control System Modeling and The Mechanical Structure Analysis For EMCVT. TELKOMNIKA Indonesian Journal of Electrical Engineering. 2013; 11(7).

[7] Yunshan Zhou, Dianlun Xue. Development of a Powertrain Control System for Parallel/Series Hybrid Electric SUV with CVT. Automo tive Enginee ring. 2008; (5): 5-9.

[8] Juanping Zhang. Research of Power System of HEV Based on 42V Power Supply. Wuhan University of Technology. 2011.

[9] Lingzhi Wu. Design of Vehicle and Study on Parameters Matching of the Powertrain System in CH7110 EV. Hefei University of Technology. 2007.

[10] Yang Chao Zhou Rong Zhang Hua. Dynamic Simulation Analysis of Electric Car Based on Cruise. New energy vehicles. 2006; (10): 7-11.

[11] Lei Lin, Yuankai Liu, Wang Ping, Fang Hong. The Electric Vehicle Lithium Battery Monitoring System, TELKOMNIKA Indonesian Journal of Electrical Engineering. 2013; 11(4): 2247-2252.

[12] Tiezhou Wu, Lunan Liu, Qing Xiao, Quan Cao, Xieyang Wang. Research on SOC estimation based on second-order RC model, TELKOMNIKA Indonesian Journal of Electrical Engineering. 2012; 10(7): 1667-1672.

[13] Haibin Jiang, Hongcheng Huang. Simulation and Optimization of the Electric Vehicle's Dynamic Performance on CRUISE. Machinery \& Electronics. 2010; (4): 60-63.

[14] B Bonsen, TWGL Klaassen, RJ Pulles, SWH Simons, M Steinbuch, Veenhuizen. Performance optimisation of the push-belt CVT by variator slip control on EV. International Journal of Vehicle Design. 2005; (3): 232-256. 